\title{
Using narratives to understand progress in youth alcohol and other drug treatment
}

Mandy Wilson, Sherry Saggers and Helen Wildy

\section{Abstract:}

Purpose: This paper aims to illustrate how narrative research techniques can be employed to promote greater understanding of young people's experiences of progress in residential alcohol and other drug treatment.

Design/methodology/approach: Narrative inquiry is used to explore client understandings of what characterises progress in treatment for young people attending a residential detoxification and a residential rehabilitation service in Perth, Western Australia. This article focuses on stories of progress collected through in-depth qualitative interviews, observation and participation with clients of the two services, over a five-month period.

Findings: Analysis of data revealed that young people were able to vividly describe their progress through treatment, and their drug taking trajectories can be conceptualised along five stages. The authors prepared narrative accounts to illustrate the features characteristic of each stage as identified by the young people. These composite narratives, written from the perspectives of young people, are presented in this article.

Practical implications: Clients' own perceptions of their journeys through drug treatment might enable staff of such services to collaborate with the young person, in shaping and positively reinforcing alternative life-stories; from those of exclusion and disconnection, to narratives of opportunity, inclusion and possibility.

Originality/value: Harmful adolescent drug and alcohol use is on the rise in Australia and elsewhere. However, our knowledge of how young people experience progress through residential treatment for substance use is limited. This paper highlights how creating narratives from young people's own stories of progress can broaden our knowledge of "what works" in residential youth alcohol and other drug treatment services. 
'Stories are like containers that hold us together; they give us a sense of coherence and continuity' (Mason-Schrock, 1996, p. 176).

Recent publicity in Australia around binge drinking by young people refocuses the attention of governments and health professionals on issues arising from problematic substance use (Australian Government 2008). Some adolescent substance use is perceived as normative in Australian culture (Prior et al., 2000) and for most use will not become problematic (Gowing et al., 2001). However, despite reduced use of particular substances among the general population in Australia, this is not so among adolescents and other subpopulations, including Indigenous Australians and young women (Australia Bureau of Statistics, 2008; Australian Institute of Health and Welfare, 2008). In countries such as the United States and Australia, initiation to drug use is occurring at an increasingly young age (Loxley et al., 2004; Masten et al., 2009; Winters, Latimer and Stinchfield, 1999).

Problematic substance use also contributes a large proportion of the total morbidity and mortality burden among young people in Australia and elsewhere (Australian Bureau of Statistics, 2008; Bellis et al., 2007; Toumbourou et al., 2008; Wagner, 2009). For this reason, understanding and addressing such use among this population is important. However, research determining 'what works' for adolescents in treatment for substance use is in its infancy, with the number of adolescent treatment outcome studies overshadowed by those devoted to adults (Brown, 2004; Bukstein and Winters, 2004; Williams and Chang, 2000).

Adolescent drug users differ from adult users. They are developmentally less mature (Brown, 2004; Bukstein and Winters, 2004), tend to have shorter histories of use (Brown, 2004), and are more likely to be poly-drug users, a pattern predictive of drug-related harms in adulthood 
(Loxley et al., 2004). The attrition rate of adolescents in residential treatment settings is higher than among adults (Colby et al., 2004) and relapse more common (Cornelius et al., 2003; Lowman 2004; Sussman, Skara and Ames, 2008). Compared with adults, young people may be less motivated to address their drug issues, and more likely to be legally coerced or experience other external pressures to undertake treatment (Bauman, Merter and Steiner, 2001; Breda and Helfinger, 2004). Therefore it cannot be assumed that programs designed for adults are directly transferrable to adolescents. Accordingly, providers of rehabilitation services for adolescents are interested in clarifying those factors that lead to retention and positive outcomes among this population when planning treatment interventions (Breda and Helfinger, 2004; Melnick et al., 1997; Wagner, 2009).

The purpose of the ethnographic research on which our article is based was to develop a picture of the progress of young people in treatment for alcohol and other drug (AOD) issues at two residential detoxification and rehabilitation services in Perth, Western Australia. Staff of the two organisations wanted to know more about what the services were achieving for their young clients. Furthermore, staff observed that young people expressed disinterest in existing progress measures (largely quantitative) and they wanted to engage young people in the process of recognising their own progress. Our project involved in-depth interviews with staff, clients and family members (Wilson, Saggers \& Wildy, 2008). However, in this article we draw on the data from young people.

\section{Using a narrative approach to understand young people's experiences of AOD treatment}

Our paper presents one aspect of a larger project: the use of a narrative methodology to elucidate young people's understandings of treatment progress. We drew on young people's stories of 
negotiating residential AOD treatment to create a series of short narratives to provide insight into how young people conceptualise their treatment experiences. We chose a narrative approach as the grounded nature of narratives make them both invitational and explanatory (Clandinin \& Connelly, 1991), which contributes to the understanding and improvement of professional practice (Noddings \& Witherell, 1991) while conveying participants' own understandings of their contexts (Shulman, 1986). Like Frank (2000) while we use story and narrative interchangeably, to us stories are what people tell, while narratives suggest a structure that storytellers themselves may not be conscious of. Thus, in this paper participants' comments are stories and our accounts of these, narratives.

In health research it is increasingly accepted that consumers comprehend their situations in the context of their social life and life course (Faltermaier, 1997) and methods that illicit these personal understandings can provide important insights for use by service providers and in public health strategies. Increasing attention is being paid to the role story-telling can play in broadening our understandings of our own and others' everyday health-related experiences. Stories in this sense then are more than just "stories as self-reports that provide more or less valid information about people's lives" (Frank 2010, p. 18). As Frank (2000, p. 357) describes, in relation to his own work on stories of ill-health, "what counts ... is not to describe the experiences of the ill but to provide resources for the ill to experience their situations differently"; stories told by those experiencing ill-health, can speak to others going through similar experiences and, aid the understanding of those who are not.

Further, narrative accounts in health-related contexts bring to life these realities, illustrating how experience and story intersect with historical, cultural, societal and institutional discourses (Lovell, 1997; Kirmayer, 2000). Central to narrative accounts of illness is the 
restructuring of an identity disrupted or fractured by the illness experience (Kirmayer, 2000;

Lovell, 1997; Frank 2010). Narrative accounts of illness thus involve a reconceptualisation of self in the face of this disruption; the result argues Frank (1993), is the generation of new perceptions of one's life.

Therapists employ narrative approaches with children and adolescents to challenge 'selflimiting life stories ... [where] different language and alternative meanings can be explored, and new stories can be authored that represent more helpful, growth promoting versions of self in relationship with others' (DeSocio, 2005: 54). Sanders (1997) asserts that these are most effective when collaboratively produced between the therapist and client. Narrative approaches are considered particularly appropriate for young people, given the developmental shifts occurring at this age and the uniqueness of the language they employ to tell their stories (Baddeley and Singer 2007; McKeough and Genereux 2003; Moffat and Johnson 2001).

\section{Context}

Our study was conducted across two services run by a large national, non-government organisation, Mission Australia, which has a network of almost 330 services throughout metropolitan, rural and regional Australia. Their purpose is to support families, young people, and the socially disadvantaged.

The services involved in our study are the only ones of their type in Western Australia. The detoxification service is situated in the city, and the rehabilitation service in a suburb east of Perth. The services house a mix of voluntary and involuntary or court-ordered clients. The detoxification service is a two week program, and the rehabilitation service is a 12 week program. 
Almost without exception the young people who went through the services at the time of the research were poly-drug users, reflecting a broader trend among adolescents in Australia (Loxley et al., 2004). Most were dealing with other issues such as a history of sexual or physical abuse, compromised health status, homelessness, self-harm and/or suicide attempts and family breakdown. While not all faced with multiple social disadvantages will experience problematic substance use, the presence of these risk factors has been shown to increase a person's susceptibility to health-damaging behaviors (Loxley et al., 2004).

\section{Method}

Data collection for this project was conducted through multiple methods. We interviewed eight young people, with equal numbers of women and men, ranging in age from 17-20 years. Three participants identified as Indigenous Australian. Five were referred through Western Australia's Drug Court Diversion process and the remaining three, self-referred [1]. Half had used one or both of the services at least once previously.

For five months, the first author divided her time between the two services, observing and participating in day-to-day activities, speaking and interacting informally with approximately 25 young people. Data were collected from a range of settings: staff meetings; graduations; daily groups on topics relating to drug use, coping strategies, and wellbeing; debrief sessions between the young people, staff, and other clients; social, sport and recreational outings; and, passing time with clients playing games and doing craft.

In-depth interviews were conducted by the first author. The young people were asked about: their understandings of the services' purpose; activities they had participated in since entering the service; how they and the staff knew they were getting better; suggestions for 
service improvement; and, hopes for the future. All interviews were transcribed verbatim to ensure accurate records for analysis. As the focus of the research was on recognising outcomes of treatment, transcripts and field-notes of observations and casual conversations were searched for descriptions the young people identified as part of 'getting better'. These were noted on cards which were coded into common themes. For example, when asked how they knew they were getting better, young people spoke of an improving psychological and emotional state, feeling happier, more confident, and liking what they saw in the mirror. These indicators were conceptualised as a framework (Table 1) and illustrated by a set of narrative accounts showing progress as described by the young people. The narratives incorporate excerpts of interview and observational data, verbatim quotes, exemplars and critical incidents to illustrate young people's understandings of their situations (Shulman, 1986). Analysis thus involved "cut[ting] stories up into small pieces in order to formulate principles of how those pieces are assembled" (Frank 2010, p. 16).

We gained ethical approval from Edith Cowan University's Human Research Ethics Committee in September 2007 and data were collected between September 2007 and January 2008. The research was carried out according to the guidelines for conducting research involving young people outlined in the Australian National Health and Medical Research Council's National Statement on Ethical Conduct in Research Involving Humans and guidelines for conducting research with people in dependent or unequal relationships (National Health and Medical Research Council, 2007). 


\section{Stories of treatment progress}

The young people spoke vividly about the services and their progress through the treatment program. Prior to entering the service, they described feeling disconnected from existing social norms. Social interactions were limited to other users, as one participant stated, 'In the drug and alcohol world your entire life is based around using ... the only life skill you learn is how to get drugs'. For another, relationships were characterised by aggression, 'a lot of hating and swearing all the time and I'm used to fighting, I'm always fighting'.

Being in a rehabilitation or withdrawal service marked them as different from their peers and represented to the young people the antithesis of what they had previously been doing. Even small, taken-for-granted acts like brushing one's teeth brought the young people back from the margins by immersing them in rituals they associated with their 'old' lives or with non-users.

Progressing through treatment involved undertaking activities, thinking and feeling the way a non-drug affected person might do, and speaking in a way that could be understood rather than 'looping off my head'. Removed for some time from their pre-drug lives or from what they perceived as the lives lived by non-users, many of the young people valued aspects of the program reinforcing their belonging in the 'unextraordinary', such as mixing with the community, and learning the skills to cope on the 'outside'. They resented activities that made them feel exceptional. Sharing public spaces with others, for example, was valued, as reflected in this participant's remark, 'We go out to parks like normal people do'.

The young people stated they were committed to travelling a different life path, claiming it was the establishment of stable relationships, obtaining employment, and the acquisition of material goods (or having the means to purchase them) that marked a departure from one's old 
life into a promising new life. The potential to achieve these goals was validated by staff, as the following comment from a young woman illustrates:

Like I've tried to get off drugs before and didn't have that much support from my family and that, and I came here and was told me I was good and smart and intelligent and could do a lot of stuff with my life and no-one's told me that before. It was stuff like, 'You're a really dumb person', family put downs and stuff and when I came here, like they told me stuff that made me feel good about myself.

Without exception, the young people desired lives of plenty (financially, materially and emotionally) rather than scarcity, and their dreams were characterised by improved relationships with their family, getting jobs, having a house and family of their own, and having money for material goods. As one young woman summed up, 'I want to, like, have money, and have my own place and pay for it with my own money, meet new people. And work....'

\section{Mapping progress stories}

When the stories were analysed it became apparent that progress through drug treatment had temporal and contextual dimensions, as do most narratives (Polkinghorne, 1988). All participants reflected back on where they 'had been', what they had passed through (and sometimes back through), where they were presently and their plans for the future. While their stories highlighted that the process involved going backwards and forwards, five thematic and temporal stages to a desired goal of a new life-story were iteratively identified along six outcome domains.

Young people spoke about being disconnected when first entering the service. When they became aware of the treatment surroundings they often actively resisted rules and pushed 
boundaries, or became silently over-compliant. All participants described experiencing a 'lightbulb' moment after spending some time in treatment (or returning for a second or third time to treatment), where they reflected on the impact of their drug use on themselves and others. Following a period of reflection, they began dreaming of a (sometimes unrealistic) future. Eventually the dream was replaced by a concrete plan and a series of actions to ensure a different, happier future.

Based on indictors identified by the young people as meaning they were 'getting better', we were able to conceptualise progress (Table 1). A young person's progress was mapped across six outcome domains, along a trajectory that led them from a state of feeling disconnected to the ultimate position of imagining an (alternative) future. It became apparent that each outcome domain included a number of occurrences/processes which appeared to be reasonably consistent across the treatment experience, even though the process, as experienced by the young people, was not always linear.

\section{Table 1: Framework for mapping treatment progress}

\section{Five narratives}

In exploring ways to represent the young people's conceptalisations of their treatment experiences - in a way that other young people may relate to and through which service providers could potentially map a young person's progress - we wrote five narratives to correspond with the process as the young people understood it. They are written from the point-of-view of the young people, using their language and stories. Threaded through the narratives are the symbols that young people employed to describe their progress. These include, initially, being disengaged from their surroundings and actively resisting the rules of the program, through to putting on 
weight, negotiating relationships with others, going fishing, having energy and money, thinking clearly, reestablishing links with family and the community, and getting a driver's license or a job.

\section{Stage 1}

The phone call. I hate this place. I want to phone my fucking boyfriend. I want to phone my boyfriend and they're treating me like a fucking three-year-old. Don't they get it? I need to talk to him. He doesn't fucking do drugs. He's not fucking doing drugs so I should be able to talk to him. I know I might have said he was using but I was off my face when I came in yesterday, I'd taken heaps and I was talking shit.

Who the fuck are these people anyway? They are fuckheads who won't let me call my boyfriend. I will fucking shout if I feel like fucking shouting. You know something else; I might be having a baby. Yep, I reckon I'm pregnant and he's the dad so they'd better just ring him for me or I'll leave. They can't do this, I'm not a prisoner. I'm going to my room and they had better fucking leave me alone.

I can't stand this much longer. What do these people want? The noise is hurting my head. I wanna know what my mates are doing. I wouldn't even be here if it wasn't for my mum and her nagging, 'How do you think Ifeel having a junkie for a daughter?' What would she know? There's no fucking way I'm going to stay here. They won't leave me alone. I don't know what they're on about. My bags are packed. I pick them up, shout at them [the staff] that they'd better back off and leave.

This narrative portrays a young person unwilling to be in treatment, disconnected from the service's daily activities. Becoming explosive when she does not get her way, she shows 
little understanding of what staff are attempting to communicate,storming off into her room and subsequently from the service.

The next narrative, in contrast, represents a client's experience of group. Groups are an integral component of the treatment program in both services. Even though the young person is not threatening to leave or throwing chairs, his behavior is non-engaged and unpredictable.

Stage 2

Group. Group happens once or twice a day. I hate it. I sit there thinking of all the things I could be doing while the worker goes on and on. The couch is too comfortable and I'm starting to nod off. What would I be doing if I was on the outside? I'm jerked back to reality by a staff member who tells me that today's group covers important stuff and it would be in my best interests to listen. In whose opinion? I graduated from Drug Facts 101 when I was 13 thanks very much. Robert's into it and he's asking the staff what they do to take their mind off things. One says she likes to cook, she finds it relaxing. Who gives a fuck! His constant questions delay the pain. I guess my groan is audible because I'm shot another warning look and then told to be more respectful of others. I extend my legs in front of me. I think I might have put on weight. These jeans are feeling a bit tight and I'm hungry all the time. I flick the elastic band I have around my wrist at Robert. It hits him on the side of the face and Jane and I have a good laugh. I lie down and put my head in Jane's lap. I'm told to sit up.

The next day a staff member says that she's noticed I have a problem with groups and suggests we talk about what I am hoping to get out of my stay. 'Groups are part of the program', 
she tells me. I reply, 'Can't I fucking do something else instead?' I explain that it'd be more worthwhile for me to clean out the kitchen cupboards. 'I've grown up around all that stuff. I know everything there is to fucking know about drugs.'

I don't know what the fuck I'm still doing here. I'm sick of them telling me what to do, stupid fucking rules. Rules are made to be broken, I say. Thank God there's no group this afternoon. We're going fishing. I don't really like fishing but it's good to get out of this place. I'm going to sit in the front of the van on the way and be in charge of the stereo. If I sit in the back with Robert I reckon I'll bash him. He asks for it.

Although this young person remains seated, he shows little engagement and distracts staff and other clients. This client thinks he knows all there is to know about drugs and finds the groups a waste of time. His behavior is inconsistent and opposed to intervention. At this stage a young person is aware of the boundaries being imposed in the treatment and attempts to push these boundaries of acceptable practice. In contrast to Stage 1, where the young person is shut off from others, the Stage 2 young person is noticing rules, other people, and the treatment.

The next narrative speaks of the third stage, which is marked by a symbolic act or a pivotal moment. The young person is beginning to let go of the past and reflect on how she arrived where she is.

\section{Stage 3}

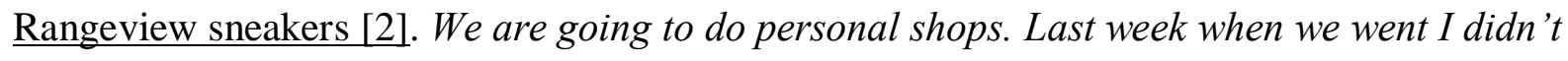
have any money. The staff here helped me get Centrelink [3] sorted out and I've been paid. I might try and find some sneakers or a new CD. Kate hasn't got cash so I said I'd buy her smokes. It really sucks when you don't have smokes in here. They break up the day. I don't 
usually make friends easy but me and Kate, we just clicked in here. It's like we've known each other forever but we only met when she came in last week.

When we get to the shops we're broken up into two groups, boys and girls, and we are going to meet up again at the kid's merry-go-round at 4pm. We're trying on sneakers. Kate is making the shop assistant nervous by jumping around in these fucking huge white shoes and screeching in this really high pitched voice. 'Do you think they're me?' The worker with us asks Kate to turn down the volume a few notches. I remember the first couple of weeks when you can't sit still, you've got energy and you're not used to it, especially if you're always on the nod. All that energy makes you act crazy. You calm down as time goes on. Your head starts getting clearer and you know more what it is you want.

When we get back I show off my new sneakers. The first thing I've bought for ages. Well apart from gear. I haven't had new clothes for a fucking long time because I never have any money. I'm used to looking scruffy. The sneakers feel good. Make me feel good. One of the staff members asks what I'm going to do with my old pair. I tell him 'these are the ones I wore in Rangeview and I'm getting fucking rid of them.' He gives me a high five.

Stage Three is characterised by a symbolic incident or reflective moment. In this narrative the young person describes a shopping trip. As the days since she last used increase, she finds that she is thinking clearly and has money to spend. The purchase of her new sneakers marks a symbolic moment where she is letting go of her old life. However, she is living in the moment and has not yet begun planning for her future.

In contrast, the fourth narrative involves a young person preparing to return to the family home. He is experiencing an improved relationship with his family and sees a future of new possibilities. 
Stage 4

Going home. Last time I lived with my family I got so fucking angry I smashed up every door in the house but when I leave here I'm going to be living with them again for the first time in five years. I broke down before I came in to this place because I had a memory from my childhood. It came from nowhere. My dad and I were fishing and I kept reeling the fish in and dad caught nothing. I remembered feeling bad that I was getting all the fish and dad wasn't. I don't know why remembering this affected me so much, it just did. More than all the other shit I put them through and there was a lot of it!

My head is clear now without the drugs. I am feeling things for the first time in five years. It can be scary but the counseling's helped. When you're on the outside, you're in this little circle and all you know and care about is drugs. Now I've realised that I can't go back to that place because it's not right for me. I'm much more confident, I'm looking good and I want to get a job. I like the night time so maybe I'll get a gig as a roadie for a famous band and travel the world? Or I could be the lead singer. Man, imagine it. It'd have to be a metal band. I only listen to metal.

It's not that things didn't piss me off in here. Some days you feel like fucking shit and I had a few moments with the staff but it's part of the process. It's like what Blake said a couple of days ago, I was battling some nasty demons when I first came in and I've come a long way. I used to be an asshole and I can make a joke now.

I can't believe I've almost made it to the end of this program; I've never completed fuckall. There's a new kid, came in this morning and I remember being where he's at. I tell him 'the first couple of weeks are hard but just stick with it'. He swears at me. 
I got my Ls [4] while I was in here and when I leave next week I'm going to see if I can drive the family back home. Maybe I'll buy a hot orange Monaro when I make money? That would pull the chicks.

This young person reflects upon changes that have occurred during his stay, such as being able to think and feel things again. He realizes a number of things about himself and his relationships with others. He is dreaming of a 'better', if unrealistic, future.

Finally, projecting into the future, the protagonist of the last narrative is embarking on her life post-treatment. Her story captures some of the aspirations of young people at the services.

\section{Stage 5}

On the outside. There've been difficult moments. Friday nights are the hardest. The phone starts ringing and it's your mates wanting you to go out. You have to make an excuse and then you need to do something to take your mind off it. I try and make sure that I'm at my auntie's place over the weekend now. She lives in the hills and there's not much to do. I used to knock around Northbridge getting high and causing mischief. Now I do fucking yoga and I'm sitting home on a Friday night. Next thing you know I'll be knitting!

I tried to give up before but when I got out last time I fell back into it straight away. I made it through a week in detox and then couldn't take it anymore. I headed straight to my mate's and we got on. The second time I made it through the program and was clean for a few weeks but I wasn't ready to give up then either and that's ok. I got back into it and not long after, I OD'd. They told me I could have died. I felt like I'd been given a second chance and this time I don't want to fuck up. 
It's about trying to keep busy and putting strategies in place. Even though I've been clean for about three months I'm still at risk. There are things I'm not strong enough to do yet and places I avoid but I focus on my future. I've enrolled to go to TAFE [5] next year to study childcare and I have a part-time job at a clothes shop over summer. One of my strengths is that I'm a people person and I love to talk. I've always wanted to work in retail so I'm stoked. I even get a $10 \%$ staff discount!

This narrative is future oriented. The young woman has recently left the service and describes how she is feeling about her life. For her giving up drugs is not a straight-forward process. Clients at Stage 5 will be determined to retain the momentum for change which was consolidated in the services. Risk is always present, and the young woman makes the most of strategies she has learnt for dealing with cravings and avoiding relapse.

\section{Discussion}

Harmful adolescent drug and alcohol use is of grave concern in Australia and elsewhere, to health professionals, young people themselves and their families (Australian Bureau of Statistics, 2008; Bellis et al., 2007; Toumbourou et al., 2007; Sussman, Skara and Ames 2008; Wagner 2009). Despite a wide range of treatment programs, we know little of how adolescents experience the treatment process in residential AOD services. Our paper seeks to address this gap, and explores the potential that narrative approaches have for illuminating how young people understand their progress through treatment. The majority of young people enjoy telling their stories (Moffat and Johnson, 2001) and story-telling provides the opportunity for the often neglected perspectives of young people to be heard (Morrill et al., 2000). 
The stories and narratives presented must be understood in the context of the program and therapeutic goals of the two services. Narratives of drug recovery are shaped by workers in treatment services (McIntosh and McKeganey, 2000) or even by others with drug issues (Steffen, 1997). Treatment (and other) services promote particular scripts and 'a relatively crystallized repertoire of story lines presents one with discernible plots, offering ways of giving shape and substance to experience in those terms' (Gubrium and Holstein, 1998, p. 166). The narratives of opportunity, inclusion and possibility in our study were collaboratively shaped and positively reinforced by staff members, highlighting and reaffirming to the young person and to others their potential participation in 'mainstream' (and rather idealised) realities from which serious drug users are typically marginalised (Van der Poel and Van de Mheen, 2006). As with Douglas's work on professional sporting athletes (2009), a narrative approach provides an opportunity to disrupt normative perceptions of particular groups of individuals.

Knowledge of young people's desire to engage with the trappings of 'mainstream' society, while itself an ideological construction, is significant, not least because it alerts workers to the need to create opportunities for these young people to embrace their desires when they leave a service. This will involve not only attention to personal circumstances (employment, housing, schooling), but to 'generative social processes that give rise to and exacerbate risk factors' (Cunneen and White 2006, p.103) to which, argue some theorists, many of these young people are exposed by virtue of being adolescent, drug users, and often in trouble with the law (Cunneen and White, 2006; Currie, 2003).

It is important to highlight that while treatment services may promote particular 'recovery' scripts, the narratives presented in this paper are intentionally written using a specific language to relay progress as described and lived by the young people in our study. They are also 
written for the potential audience - young people themselves. The storytelling nature of the accounts can engage readers (when either read themselves or read to them) and offer them a way to relate and understand the material through the plausibility and conviction of a young person's voice; a young person who has been there before them. Written in this way, it is possible young people will come to 'care about the events recounted' in the stories and consider the struggle to arrive at the later stages worth the effort (Garro and Mattingly, 2000, p.11).

\section{Potential benefits for staff of treatment services}

The creation of narratives is a collaborative process (Mason-Schrock, 1996) and young people expressed a strong desire to change their personal and environmental circumstances, a finding mirrored elsewhere (Currie, 2003; McIntosh and McKeganey, 2001; Ehrmin, 2002). This provides staff members opportunities to work with young people to construct new or revised storylines for their lives. A narrative approach can be effective for formulating reshaped stories to articulate new environments or changed circumstances (Meldrum, Tsao and Zeltzer, 2009; Olson and Craig, 2009). Meldrum and colleagues (2009) suggest a clinician can use children's narratives of chronic pain to show 'his/her understanding of the individual narrative, make it a basis for suggesting a new plot direction and for supporting the child's own ability to make positive changes and commit to a better life' (p. 1032). Like children disrupted by chronic illness, the trajectory of adolescence into young adulthood for participants in our study has been disrupted by chronic drug use. However, these young people are actively constructing new biographical scripts for themselves. Staff can assist in co-creating, encouraging, and reaffirming or 'authorising' a coherent story through the use of narratives which can offer the individual alternative possibilities (Meldrum, Tsao and Zelter, 2009; Kiramayer, 2000). 
Possible further uses for narratives such as ours include the ability to individualise treatment intervention for clients. Motivations, progress through treatment, and modification of problem behaviour are frequently conceptualised along a 'stages of change' model, the main organising principle of the Transtheoretical Model (Prochaska and DiClemente, 1992; Prochaska and Velicer, 1997). This model is posits a process of change over a series of discrete stages, from an absence of intention to change (Precontemplation), through conscious concern about impacts of use (Contemplation), to planning strategies to change (Preparation), to acting on these strategies (Action), and culminating with continuation of positive change (Maintenance) (DiClemente, Schlundt and Gemmel, 2004). Movement through these stages can involve going backwards and forwards, but central to the model is the idea that specific interventions can be stage-matched to promote forward movement to the next discrete stage (Prochaska and DiClemente, 1992).

While most stages of change models for treatment of substance use apply to adult populations (Callaghan, Hathaway et al., 2005), our narratives encompass a similar stages-ofchange-process - a process with which most staff are familiar - adapted specifically to young people's understandings of their health-changing behaviors; the potential for continuous improvement of service delivery and development becomes apparent. If a client can recognise themselves in the stories and plot their progress, staff will have more understanding of the stageeffect (Prochaska and Velicer, 1997) and the plan of action can be better attuned to the individual experience of treatment. For example, a young person in Stage One or Two is unlikely to embrace a group session exploring skills for a non-using life. In this case, the physical space of the service and exposure to the 'ordinariness' of the everyday routine may be the intervention in 
itself. A young person who is in Stage Four, on the other hand, will tend to respond positively to activities and strategies which increase their potential to realise their dreams.

\section{Possible benefits for the young person}

Narratives as presented in our paper 'carry the implicit promise that a new identity is available to others undergoing the same epiphanal experiences, and possibly available even to those who have not' (Frank, 1993, p. 42). The young people might be able to see themselves (or potential selves) in one narrative and not in another, and as time progresses come to re-conceptualise their own stories (Taïeb et al., 2008). Narratives are transformative (Connelly and Clandinin, 2000) and adolescents and young adults are particularly disposed to social influences that shape the stories they share (Baddeley and Singer, 2007). Adolescence is a key developmental phase for the creation of biographical stories and young people's ability to tell meaningful stories about their lives and selves increases during this period. In our study, the young people's experiences of drug use and recovery (whether temporary or sustained) became embedded in the stories they used to speak of their lives.

Preliminary discussions with clients and staff at the services where the research was conducted indicated that the stories resonated with them as both providers and consumers; the applicability of short narratives for use as part of an outcomes measurement tool is currently being established in a subsequent research project funded through an Australian Research Council grant. The second stage of the research project involves exploring the possibility of embedding stories into practice settings as a means for measuring young people's progress through treatment (Roarty et al., In press).

All research has limitations. Some studies suggest that the complexity given to selfnarratives and the development of coherent thematic storytelling increases in later adolescence 
(Habermas and Bluck, 2000; McKeough and Genereux, 2003). Participants in our study were older adolescents on the verge of young adulthood. In part, this was because of the availability of clients at the time of the study, but was also influenced by staff perceptions of those considered articulate and ready to participate in the research. Some treatment services can have clients as young as 12 , and the relevance and suitability of the narratives for these young people remains to be tested. However, introducing children and adolescents who do not yet recognise the concept of life narrative to the narratives of others can facilitate a process of recognition and, in turn, aid them in the eventual formation of their own stories (Habermas and Bluck, 2000).

The pilot nature of the project and the small numbers of clients moving through the services did not permit us to remain in the field until saturation was achieved. Additionally, all participants interviewed continued on to complete treatment and were able to reflect upon where they had come; it remains to be seen if young people experiencing more immediate tumultuous circumstances find the narratives useful. The findings of this project are currently being tested in a number of residential AOD settings across Australia with a larger and more diverse sample of young people.

Finally, that more than half of the interviewed clients were referred through Western Australia’s Drug Court Diversion process might have influenced the results. These clients graduated from the programs, and avoiding jail was volunteered as a strong, but not the only, motivating factor for program compliance. Knowledge of what motivates adolescents in different treatment settings is limited (Battjes et al., 2003; Breda and Hilfinger, 2004). Some research suggests adolescents are less motivated to change than adults, and those coerced into treatment (both adolescents and adults) also have less intrinsic motivation for change (De Leon, Melnick and Hawke, 2000). However, other research among adults has shown that legally coerced clients 
might be even more motivated to change than voluntary clients (Gregoire and Burke, 2004). The premature exit of other court ordered and self-referred individuals during the research period suggests that it is a combination of diverse factors, for example, referral method, number of admissions, the impact of substance use on other areas of an individual's life and developmental stage (Battjes et al., 2003; Breda and Helfinger, 2004), which influences how young people progress in treatment and their level of motivation to change. However, more research is needed to assess the motivations and experiences of various subgroups, including adolescents coerced into treatment (Battjes et al., 2003).

\section{Conclusion}

Young people's stories of progress provide a potentially important contribution to our understanding of how they experience the process of residential treatment and complements therapeutic approaches already in use with young people. The narratives we created employ a language used by the young people, and others coming through the services will be potentially able to understand, relate to and use the narratives to help plot their own processes and (re)articulate their life stories; a process in which staff can play a significant role. However, while staff can support these young people to strive for an alternative future while they are in the service and for a limited period after they leave, opportunities must exist to make this future a reality. This will involve addressing broader structural and societal discourses that act to marginalise these young people. Most significantly, our research addresses the dearth in studies of the experiences of young people in residential treatment. Problematic substance use among adolescents in many parts of the world is increasing and so the need for treatment services for 
this population is increasing. Understanding how young people experience the treatment process is critical for responding appropriately and effectively to adolescent substance misuse.

\section{Notes}

1. By self-referred we mean clients who did not enter treatment through the court system. However, as the literature shows young people are more likely than adults to experience other external coercions, including by family members.

2. Rangeview is the name of a youth detention center in Perth, Western Australia.

3. Centrelink is the Australian agency responsible for benefit payments.

4. 'L's' stand for Learner's Permit, the permit that is issued prior to learning to drive a motor vehicle.

5. TAFE stands for Technical and Further Education. TAFE institutions offer a wide variety of vocational tertiary education courses in Australia.

\section{References}

Australia Bureau of Statistics. (2008), Australian Social Trends, 2008 (No. 4102.0), Australian Bureau of Statistics, Canberra, available at: 
http://www.abs.gov.au/AUSSTATS/abs@.nsf/Lookup/4102.0Chapter5002008 (accessed $212011)$

Australian Institute for Health and Welfare. (2008), National Drug Strategy Household Survey: First results (Drug Statistics Series No. 20, Cat. No. PHE 98), Australian Institute of Health and Welfare, Canberra.

Australian Government. (2008), The National Binge Drinking Campaign, Department of Health and Ageing, Canberra, available at: http://www.drinkingnightmare.gov.au/internet/DrinkingNightmare/publishing.nsf, (accessed 11 April 2012)

Baddeley, J. and Singer, J. (2007), “Charting the life story's path: Narrative identity across the life span”, in D. J. Clandinin (Ed.), Handbook of Narrative inquiry: Mapping a Methodology, Sage Publications, Thousand Oaks, pp. 177-202.

Battjes, R., M. Gordon, K. O’Grady, T. Kinlock and Carswell, M. (2003), "Factors that predict adolescent motivation for substance abuse treatment”, Journal of Substance Abuse Treatment, Vol. 24, pp. 221-232.

Bauman, S., Merta, R. J. and Steiner, R. (2001), "The development of a measure of motivation to change in adolescent substance users: Preliminary findings", Journal of Child and Adolescent Substance Abuse, Vol. 11 No. 2, pp. 19-39.

Bell, J. (2002), "Narrative inquiry: More than just telling stories”, TESOL Quarterly, Vol. 36 No. 2, pp. 207-213.

Bellis, M., Hughes, K., Morleo, M., Tocque, K., Hughes, S., Allen, T, et al. (2007), "Predictors of risky alcohol consumption in schoolchildren and their implications for preventing alcohol-related harm”, Substance Abuse Treatment, Prevention and Policy, Vol. 2 No. 
15, available from: http://www.substanceabusepolicy.com/content/pdf/1747-597X-215.pdf doi:10.1186/1747-597X-2-15, (accessed 11 April 2012).

Breda, C. and Helfinger, C. (2004), "Predicting incentives to change among adolescents with substance abuse disorder", The American Journal of Drug and Alcohol Abuse, Vol. 30 No. 2, pp. 251-267.

Brown, S. (2004), "Measuring youth outcomes from alcohol and drug treatment", Addiction, Vol. 99 Suppl. 2, pp. 38-46.

Bukstein O. G. and Winters, K. (2004), "Salient variables for treatment research of adolescent alcohol and other substance use disorders", Addictions, Vol. 99 Suppl. 2, pp. 23-37.

Callaghan, R., Hathaway, A., Cunningham, J., Vettese, L., Wyatt, S. and Taylor, L. (2005), "Does stage-of-change predict dropout in a culturally diverse sample of adolescents admitted to inpatient substance-abuse treatment? A test of the Transtheoretical Model", Addictive Behaviors, Vol. 30, pp. 1834-1847.

Clandinin, D. J. and Connelly, F. M. (2000), Narrative inquiry: Experience and Story in Qualitative Research, Jossey-Bass, San Francisco.

Connelly, F. M. and Clandinin, D. J. (1990), "Stories of experience and narrative inquiry", Educational Researcher, Vol. 19 No. 5, pp. 2-14.

Cornelius, J., Maisto, S., Pollock, N., Martin, C.,Salloum, I., Lynch, K. et al. (2003), "Rapid relapse generally follows treatment for substance use disorders among adolescents", Addictive Behaviors, Vol. 28, pp. 381-386.

Cunneen, C. and White, R. (2006), Australia: control, containment or empowerment? in J. Muncie and B. Goldson (eds.), Comparative Youth Justice: Critical Issues, Sage Publications, London, pp. 96-110. 
Currie, E. (2003), “'It's our lives they're dealing with here': some adolescent views of residential treatment", The Journal of Drug Issues, Vol. 33 No. 4, pp. 833-864.

De Leon, G., Melnick, G. and Hawke, J. (2000), “The motivation-readiness factor in drug treatment: Implications for research and policy", Advances in Medical Sociology, Vol. 7, pp. 103-129.

DeSocio, J. (2005), “Accessing self-development through narrative approaches in child and adolescent psychotherapy”, Journal of Child and Adolescent Psychiatric Nursing, Vol. 18, No. 2, pp. 53-61.

DiClemente, C., Schlundt, D. and Gemmell, L. (2004), "Readiness and stages of change in addiction treatment", The American Journal on Addiction, Vol. 13, pp. 103-119.

Douglas, K. (2009) "Storying my self: negotiating a relational identity in professional sport", Qualitative Research in Sport and Exercise, Vol. 1, No. 2, pp. 176-190.

Faltermaier T. (1997) "Why public health research needs qualitative approaches", European Journal of Public Health, Vol 7, pp. 357-363.

Frank, A. (1993), "The rhetoric of self-change: illness experience as narrative", The Sociological Quarterly, Vol. 34 No. 1, pp. 39-52.

Frank, A. (2000), "Standpoint of storyteller", Qualitative Health Research, Vol. 10, No. 3, pp. $354-365$.

Frank, A. (2010), Letting Stories Breathe: A socio-narratology. The University of Chicago Press, Chicago.

Garro, L. (1984), "Narrative representations of chronic illness experience: cultural models of illness, mind, and body in stories concerning the temporomandibular joint (TMJ)", Social Science and Medicine, Vol. 38 No. 6, pp. 775-788. 
Garro, L. and Mattingly, C. (2000), "Narrative as construct and construction", in C. Mattingly and Garro, L. (eds.), Narrative and the Cultural construction of Illness and Healing. University of California Press, Berkley and Los Angeles, pp. 1-49.

Gowing, L., Proudfoot, H., Henry-Edwards, S. and Teesson, M. (2001), Evidence supporting treatment: The effectiveness of interventions for illicit drug use, Australian National Council of Drugs, Canberra.

Gregoire, T. and Burke, A. (2004), "The relationship of legal coercion to readiness to change among adults with alcohol and other drug problems", Journal of Substance Abuse Treatment, Vol. 26, pp. 35-41.

Gubrium, J. and Holstein, J. (1998), "Narrative practice and the coherence of personal stories", The Sociological Quarterly, Vol. 39 No. 1, pp. 163-187.

Habermas, T. and Bluck, S. (2000), "Getting a life: The emergence of the life story in adolescence", Psychological Bulletin, Vol. 126, pp. 748-769.

Kirmayer, L. (2000), "Broken narratives: clinical encounters and the poetics of illness experience", in C. Mattingly, and L. Garro (eds.), Narrative and the Cultural construction of Illness and Healing, University of California Press, Berkley and Los Angeles, p. 153-180.

Lapum, J., Angus, J., Peter, E. and Watt-Watson, J. (2010), “Patients' narrative accounts of open-heart surgery and recovery: Authorial voice of technology”, Social Science and Medicine, Vol. 70 No. 5, pp. 754-762.

Lovell, A. (1997), “"The city is my mother': narratives of schizophrenia and homelessness", American Anthropologist, Vol. 99 No. 2, pp. 355-368. 
Lowman C. (2004), "Developing effective evidence-based interventions for adolescents with alcohol use disorders", Addiction, Vol. 99, Suppl. 2, pp. 1-4.

Loxley, W. J., Toumbourou, J., Stockwell, T., Haines, B., Scott, K., Godfrey, C. et al. (2004), The prevention of substance use, risk and harm in Australia: A review of the evidence, Department of Health and Ageing, Canberra.

Mason-Schrock, D. (1996), “Transsexual's narrative construction of the 'true self", Social Psychology Quarterly, Vol. 59 No. 3, pp. 176-203.

McIntosh, J. and McKeganey, N. (2001), "Identity and recovery from dependent drug use: the addict's perspective", Drugs: Education, Prevention and Policy, Vol. 8 No. 1, pp. 48-59.

McKeough, A. and Genereux, R. (2003), "Transformation in narrative thought during adolescence: The structure and content of story compositions", Journal of Educational Psychology, Vol. 95 No. 3, pp. 537-552.

Meldrum, M., Tsao, J. and Zeltzer, L. (2009), “'I can’t be what I want to be': Children's narratives of chronic pain experiences and treatment outcomes". Pain Medicine, Vol. 10 No. 6, pp. 1018-1034.

Melnick, G., De Leon, G. Hawke, J., Jainchill, N. and Kressel, D. (1997), "Motivation and readiness for Therapeutic Community Treatment among adolescents and adult substance abusers", The American Journal of Drug and Alcohol Abuse, Vol. 23 No. 4, pp. 485-506.

Moffat, B. and Johnson, J. (2001), “Through the haze of cigarettes: Teenage girl's stories about cigarette addiction", Qualitative Health Research, Vol. 11, pp. 668-681.

Morrill, C., Yalda, C., Adelman, M., Musheno, M. and Bejarano, C. (2000), "Telling tales in school: youth culture and conflict narratives". Law and Society Review, Vol. 34 No. 3, pp. 521-565. 
National Health and Medical Research Council. (2007), National statement on ethical conduct in research involving humans, National Health and Medical Research Council, Canberra. Ning, A. (2005), "Games of truth: rethinking conformity and resistance in narratives of heroin recovery", Medical Anthropology, Vol. 24 No. 4, pp. 349-382.

Noddings, N. and Witherell, L. (1991), Epilogue "Themes remembered and foreseen", in N. Noddings and Witherell, L. (Eds). Stories Lives Tell. Narrative and Dialogue in Education. Teachers College Press, New York, pp. 279-280.

Olson, M. and Craig, C. (2009), "Small stories and meganarratives: Accountability in balance", Teachers College Record, Vol. 111 No. 2, pp. 547-572.

Persson, A. (2005), "Facing HIV: Body shape change and the (in)visibility of illness", Medical Anthropology, Vol. 24, pp. 237-264.

Polkinghorne, D. (1988), Narrative Knowing and the Human Sciences. State University of New York Press, Albany.

Polkinghorne, D. (2007), "Validity issues in narrative research", Qualitative Inquiry, Vol. 13, pp. 471-486.

Prior, M., Sanson A., Smart, D. and Oberklaid, F. (2000), Pathways from infancy to adolescence: Australian Temperament Project 1983-2000 (Research Report no 4), Australian Institute of Family Studies, Canberra.

Prochaska, J. O. and Velicer, W. F. (1997), “The Transtheoretical Model of Health Behavior Change", American Journal of Health Promotion, Vol. 12 No. 1, pp. 38-48.

Prochaska, J.O., DiClemente, C. and Norcross, J. (1992), "In search of how people change: Applications to addictive behavior", American Psychologist, Vol. 47 No. 9, pp. 11021014. 
Roarty, L., Wildy, H., Saggers, S., Conigrave, K., Wilson, M., Di Nicola, K. et al., (In Press) 'My Journey Map': Developing a qualitative approach to mapping young people's progress in residential rehabilitation, Contemporary Drug Problems.

Sanders, C. (1997), "Re-Authoring Problem Identities: Small Victories with Young Persons Captured by Substance Misuse", in C. Smith and D. Nylund (eds.), Narrative Therapies with Children and Adolescents. New York and London, The Guildford Press, pp. 400422.

Singer, M., Scott, G., Wilson, S., Easton, D. and Weeks, M. (2001), “'War Stories”: AIDS prevention and the street narratives of drug users", Qualitative Health Research, Vol. 11 No. 5, pp. 589-611.

Shulman, L. (1986). "Those who understand: knowledge growth in teaching”, Educational Researcher, Vol. 15, No. 2, pp. 4-14.

Smith, B. and Sparkes, A. (2008), "Changing bodies, changing narratives and the consequences of tellability: a case study of becoming disabled through sport", Sociology of Health and Illness, Vol. 30 No. 2, pp. 217-236.

Smith, N., Mitton, C. and Peacock, S. (2009), "Qualitative methodologies in health-care priority setting research", Health Economics, Vol. 18, pp. 1163-1175.

Steffen, V. (1997), “Life stories and shared experience”, Social Science and Medicine, Vol. 45 No. 1, pp. 99-111.

Sussman, S., Skara, S. and Ames, S. (2008), "Substance abuse among adolescents”, Substance Use and Misuse, Vol. 43, pp. 1802-1828. 
Taïeb, O., Révah-Lévy, A., Moro, M. and Baubet, T. (2008), “Is Ricoeur's Notion of Narrative Identity Useful in Understanding Recovery in Drug Addicts?" Qualitative Health Research, Vol. 18, pp. 990- 1000.

Toumbourou, J., Stockwell, T., Neighbors, C., Marlatt, G., Sturge J. and Rehm, J. (2007), "Interventions to reduce harm associated with adolescent substance use", The Lancet, Vol. 369 No. 9570, pp. 1391- 1401.

Van der Poel, A. and Van de Mheen, D. (2006), "Young people using crack and the process of marginalization", Drugs: Education, Prevention and Policy, Vol. 13 No. 1, pp. 45-59.

Wagner, E. (2009), "Improving treatment through research: Directing attention to the role of development in adolescent treatment success", Alcohol Research and Health, Vol. 32 No. 1, pp. 67-75.

Williams, R. and Chang, S. (2000), “A comprehensive and comparative review of adolescent substance abuse treatment outcome”, Clinical Psychology: Science and Practice, Vol. 7 No 2, pp. 138-166.

Wilson, M., Saggers, S. and Wildy, H. (2008), Outcome measures for young people attending substance misuse services for detoxification and residential rehabilitation in Perth, Western Australia, Edith Cowan University, Centre for Social Research, Perth.

Winters, K., Latimer, W. and Stinchfield, R. (1999), “Adolescent treatment”, in P. Ott, R. Tarter and R. Ammerand (eds.), Sourcebook on Substance Abuse: Etiology, Epidemiology, Assessment and Treatment, Allyn and Bacon, Boston, MA, pp. 350-361. 
Further references for acknowledgement:

Clandinin, D.J. and Connelly, F.M. (1991), "Narrative story in practice and research", in Scho"n, D. (Ed.), The reflective turn: Case studies in education practice, Teachers College Press, NY.

Erhmin, J.T. (2002), "That feeling of not feeling: Numbing the pain for substance dependent African American women", Qualitative Health Research, Vol. 12, pp. 780-791. 